\title{
Impact of using a local protocol in preoperative testing: blind randomized clinical trial.
}

\section{Impacto do uso de um protocolo local na solicitação de exames pré-operatórios: ensaio clínico randomizado cego.}

\author{
Mônica loureiro Santos'; Antônio Carlos Iglesias ${ }^{1,2}$.
}

\begin{abstract}
A B S T R A C T
Objective: to evaluate the impact of the use of a local protocol of preoperative test requests in reducing the number of exams requested and in the occurrence of changes in surgical anesthetic management and perioperative complications. Methods: we conducted a randomized, blinded clinical trial at the Gaffrée and Guinle University Hospital with 405 patients candidates for elective surgery randomly divided into two groups, according to the practice of requesting preoperative exams: a group with non-selectively requested exams and a protocol group with exams requested according to the study protocol. Studied exams: complete blood count, coagulogram, glycemia, electrolytes, urea and creatinine, ECG and chest X-ray. Primary outcomes: changes in surgical anesthetic management caused by abnormal exams, reduction of the number of exams requested after the use of the protocol and perioperative complications. Results: there was a significant difference $(p<0.001)$ in the number of exams with altered results between the two groups (14.9\% vs. 29.1\%) and a reduction of $57.3 \%$ in the number of exams requested between the two groups ( $<0.001)$, which was more pronounced in patients of lower age groups, ASA I, without associated diseases and submitted to smaller procedures. There was no significant difference in the frequency of conduct changes motivated by the results of exams or complications between the two groups. In the multivariate analysis, complete blood count and coagulogram were the only exams capable of modifying the anesthetic-surgical management. Conclusion: the proposed protocol was effective in eliminating a significant number of complementary exams without clinical indication, without an increase in perioperative morbidity and mortality.
\end{abstract}

Keywords: Preoperative Care. Practice Guidelines as Topic. Laboratory Test. Postoperative Complications.

\section{INTRODUCTION}

Ts he preoperative evaluation (POE) seeks to promote safety in surgery and anesthesia, to ensure a better quality of care, as well as the rational use of resources in the perioperative period. Thus, history and physical examination should be considered the main components of the $\mathrm{POE}$, with the complementary exams remaining under specific clinical conditions ${ }^{1-3}$.

In general, patients who are candidates for elective operations have requested preoperative complementary exams (POCE) routinely and indifferently to the clinical findings of the POE. This is based on several factors, such as: ability to identify diseases not diagnosed by anamnesis and physical examination, safety assurance to the professionals involved in the process to make decisions regarding the resolution of intercurrences, as well as safeguarding possible legal responsibilities ${ }^{4}$. However, the medical literature has indicated that abnormalities found in POCEs are not usually clinically important, are generally ignored, do not contribute to changes in the anesthetic-surgical management and are not related to perioperative complications. In addition, there is a risk that non-clinically based tests, especially on the occurrence of false positives, may lead to further invasive investigations, leading to postponement of operations as well as inadequate treatment ${ }^{3,5}$.

Regarding selected exams, more controlled clinical research is needed ${ }^{6}$. The rationalization of the request for complementary exams in the POE still requires studies, and to this end, emerged evidence-based guidelines $1,2,7-9$ and protocols constructed in view of presence of associated diseases and the procedures to be performed ${ }^{1,2}$. Some authors show that the implementation of protocols increases the effectiveness of the requests for exams without affecting patient's safety and the morbidity of the surgical-anesthetic procedure ${ }^{10,11}$.

1 - Gaffree and Guinle University Hospital, Federal University of the State of Rio de Janeiro, Service of Anesthesiology, Rio de Janeiro, Rio de Janeiro State, Brazil. 2 - School of Medicine and Surgery, Federal University of the State of Rio de Janeiro, Service of General and Specialized Surgery, Rio de Janeiro, Rio de Janeiro State, Brazil. 
The objective of this study was to evaluate the use of a local protocol of preoperative examination requests in the $\mathrm{POE}$, including its impact on the number of requested exams, the occurrence of changes in anesthetic-surgical management and the frequency of perioperative complications.

\section{METHODS}

This is a blinded, randomized clinical trial conducted at the Gaffrée and Guinle University Hospital (HUGG) of the Federal University of the State of Rio de Janeiro (UNIRIO), between March 2014 and July 2015, and approved by the Ethics in Research Committee under the Number 27505514400005258. All patients signed an Informed Consent Form.

The population comprised patients who were candidates for surgical procedures in General Surgery, Digestive Surgery and Coloproctology (here grouped as General Surgery), Urology, Gynecology, Thoracic Surgery, Vascular Surgery, Otorhinolaryngology, Orthopedics, Neurosurgery, Plastic Surgery and Ophthalmology. The inclusion criteria were age greater than or equal to 18 years, elective operation, and preoperative evaluation conducted at the HUGG Preoperative Evaluation Clinic. Exclusion criteria were age less than 18 years, emergency/ urgency operations, ASA IV or V and those whose preoperative evaluation was done in another hospital. The POE consultations were performed at least 15 days before the operation and followed the guidelines of the American Society of Anesthesiologists (ASA)' .

The study participants were randomly divided by simple randomization into: Routine Group (RG), in which the routine preoperative complementary exams were requested before POE consultation, and Protocol Group (PG), whose request for exams was Based on the POE consultation following the Preoperative Exam Request Protocol (Figure 1), developed by the researcher according to the guidelines of the ASA Task Force'. The POCE included in this study were complete blood count (CBC), prothrombin (PT and INR) and activated partial thromboplastin time (aPTT), serum electrolytes concentration (sodium, potassium and chlorine), glucose, urea and creatinine, resting electrocardiogram (ECG) and chest radiography. All data on history, physical examination and test results were recorded on individual preoperative assessment sheets in addition to data from complementary exams that were not part of the protocol, but were deemed necessary and requested by the POE conductor (supplementary examinations).

On the day of the surgical procedure, after discharge from the post anesthetic recovery (PAR) room, all patients underwent an evaluation by anesthesiologists responsible for the anesthetic procedure with observation and recording of the following parameters: alteration in surgical anesthetic management (cancellation of the procedure, change in anesthetic and/or surgical technique or change in postoperative care) due to absence or abnormal results of preoperative exams (outcome 1) and/or complications, during the anesthetic-surgical procedure or in the period between the patient leaving the operating room until discharge from the PAR room (outcome 2). Complications considered were hypotension (systolic blood pressure $\leq 80 \mathrm{mmHg}$ ), cardiac arrhythmia in a patient with no previous history or worsening of preexisting disorder requiring treatment, hypertension (systolic blood pressure $\geq 200 \mathrm{mmHg}$ or diastolic $\mathrm{BP} \geq 110 \mathrm{mmHg}$ ) and cardiorespiratory arrest. These last three were grouped, for statistical purposes, as other cardiovascular complications. Respiratory complications were thus grouped: hypoxemia $\left(\mathrm{SATO}_{2} \leq 90 \%\right.$ or $\mathrm{PaO}_{2}$ $\leq 100 \mathrm{mmHg}$ ), laryngospasm, bronchospasm, thoracic stiffness, residual curarization and difficulty of orotracheal intubation (OTI). Shock, regardless of the cause, was also included, and a group of general complications (nausea and vomiting, inadequate pain control, prolonged awakening, agitation on awakening, hypoglycemia, and total or partial block failure).

Other variables studied were the total number of exams requested, the number of exams with abnormal results, the number of exams additional to the protocol, and the difference between the total and individualized number of exams requested between the two groups.

The sample calculation was performed based on the historical average of the last 24 months of the number of patients seen at the POE/HUGG Clinic and considered 
Table 1. Demographic and clinical data.

\begin{tabular}{|c|c|c|c|}
\hline Features & $\begin{array}{c}\text { Routine Group (n=204) } \\
\text { n (\%) }\end{array}$ & $\begin{array}{c}\text { Protocol group ( } \mathrm{n}=201) \\
\mathrm{n}(\%)\end{array}$ & $p$-value \\
\hline Gender & & & 0.176 \\
\hline Female & $127(62.3)$ & $135(67.2)$ & \\
\hline Male & $77(37.7)$ & $66(32.8)$ & \\
\hline Age group & & & 0.255 \\
\hline 18 to 59 years & $106(48.6)$ & $112(51.4)$ & \\
\hline$\geq 60$ years & $98(52.4)$ & $89(47.6)$ & \\
\hline \multicolumn{4}{|l|}{ Associated Diseases } \\
\hline None & $62(51.2)$ & $59(48.8)$ & 0.939 \\
\hline HAS & $93(45.6)$ & $107(53.2)$ & 0.075 \\
\hline Obesity & $63(30.9)$ & $53(26.4)$ & 0.374 \\
\hline Diabetes & $20(9.8)$ & $22(10.9)$ & 0.415 \\
\hline Pneumopathy & $21(10.3)$ & $15(7.5)$ & 0.677 \\
\hline Dyslipidemia & $15(7.4)$ & $12(6.0)$ & 0.360 \\
\hline Cardiopathy & $12(5.9)$ & $5(2.5)$ & 0.072 \\
\hline ASA & & & 0.213 \\
\hline (I) & $55(49.5)$ & $56(50.5)$ & 0.213 \\
\hline$\|$ & $137(52.5)$ & $124(47.5)$ & \\
\hline III & $12(36.4)$ & $21(63.6)$ & \\
\hline MET & & & 0.180 \\
\hline MET $<4$ & $22(10.8)$ & $31(15.4)$ & \\
\hline $\mathrm{MET} \geq 4$ & $140(68.6)$ & $121(60.2)$ & \\
\hline $\mathrm{MET} \geq 10$ & $42(20.6)$ & $49(24.4)$ & \\
\hline Surgery size & & & 0.149 \\
\hline Minor & $61(29.9)$ & $62(30.8)$ & \\
\hline Medium & $107(52.5)$ & $117(58.2)$ & \\
\hline Major & $36(17.6)$ & $22(10.9)$ & \\
\hline \multicolumn{4}{|l|}{ Anesthesia } \\
\hline General & $78(38.2)$ & $87(43.3)$ & 0.116 \\
\hline Spinal * & $68(33.3)$ & $66(32.8)$ & \\
\hline Regional \# & $20(9.8)$ & $23(11.4)$ & \\
\hline General+ Spinal or regional & $31(15.2)$ & $17(8.5)$ & \\
\hline Local + Sedation & $5(2.5)$ & $7(3.5)$ & \\
\hline
\end{tabular}

* spinal or epidural anesthesia; \# brachial plexus or peribulbar; SAH: systemic arterial hypertension; ASA: physical status according to the American Society of Anaesthesiologists; Met: metabolic equivalents (activity index of Duke). 
the calculation methodology for finite population samples and sampling procedures without replacement, with probability of occurrence of the selected outcomes in 50\%, with 95\% confidence interval, and type I error $\leq 5 \%$; The estimated sample was 329 patients.

We carried out univariate analyzes by means of simple frequencies to describe the evaluated sample and bivariate analyzes to verify the difference in the distribution of the independent variables for each outcome of interest using the chi-square test. We expressed quantitative variables as mean and standard deviation, and qualitative variables, as percentage. To evaluate the association between the variables of interest, were calculated the gross Odds Ratio with a 95\% confidence interval through nonconditional logistic regression. We performed all statistical analyzes using the statistical package SPSS ${ }^{2} 17.0$ (Statistic Package for the Social Science, Chicago, IL, 2008).

\section{RESULTS}

Of the 500 initially recruited consecutive patients, six refused to participate in the study and three did not meet the research criteria. The remaining 491 were then randomly allocated in the two study groups. The RG initially received 252 patients, however, 48 were ineligible because their operations were canceled for various reasons (change in surgical management, personal reasons, administrative reasons), leaving a total of 204 patients. The PG had initially 239 patients, but ended with 201 patients for the same aforementioned reasons. There was no statistically significant difference between the two groups regarding gender, age, associated diseases, MET, ASA, surgical size and type of anesthesia (Table 1).

There were 1428 POCE in the RG and 601 exams in the PG, of which $14.9 \%$ and $29.1 \%$ were altered in the

Table 2. Distribution of results by analysis group.

\begin{tabular}{|c|c|c|c|}
\hline Features & $\begin{array}{c}\text { Routine Group (n=204) } \\
n(\%)\end{array}$ & $\begin{array}{c}\text { Protocol Group }(n=201) \\
n(\%)\end{array}$ & p-value \\
\hline $\mathrm{CBC}$ & & & 0.009 \\
\hline Normal & $165(80.9)$ & $88(60.8)$ & \\
\hline Altered & $39(19.1)$ & $40(31.3)$ & \\
\hline Electrolytes & & & 0.427 \\
\hline Normal & $200(98.0)$ & 48 (100.0) & \\
\hline Altered & $4(2.0)$ & $0(0.0)$ & \\
\hline Urea/Creatinine & & & 0.005 \\
\hline Normal & $197(96.6)$ & $120(88.9)$ & \\
\hline Altered & $7(3.4)$ & $15(11.1)$ & \\
\hline PT/aPTT & & & 0.008 \\
\hline Normal & $198(97.1)$ & $17(81.0)$ & \\
\hline Altered & $6(2.9)$ & $4(9.0)$ & \\
\hline Blood glucose & & & 0.001 \\
\hline Normal & $181(78.8)$ & $16(45.7)$ & \\
\hline Altered & $43(21.2)$ & $19(54.3)$ & \\
\hline EKG & & & 0.427 \\
\hline Normal & $129(63.2)$ & $88(61.5)$ & \\
\hline Altered & $75(36.8)$ & $55(38.5)$ & \\
\hline Chest $x$-rays & & & 0.001 \\
\hline Normal & $164(80.4)$ & $49(53.8)$ & \\
\hline Altered & $40(19.6)$ & $42(43.2)$ & \\
\hline Total tests & & & 0.001 \\
\hline Normal & $1214(85.1)$ & $426(70.1)$ & \\
\hline Altered & $214(14.9)$ & $175(29.1)$ & \\
\hline
\end{tabular}

PT/aPTT: prothrombin timelactivated thromboplastin time; EKG-electrocardiogram at rest. 
Table 3. Conduct changes and complications.

\begin{tabular}{lcccc}
\hline & $\begin{array}{c}\text { Routine Group } \\
(\mathrm{n}=204) \\
\mathrm{n}(\%)\end{array}$ & $\begin{array}{c}\text { Protocol group } \\
(\mathrm{n}=201) \\
\mathrm{n}(\%)\end{array}$ & $\begin{array}{c}\text { Total } \\
\mathrm{n}(\%)\end{array}$ & p-value \\
\hline $\begin{array}{l}\text { Conduct Alteration } \\
\text { No }\end{array}$ & $199(97.5)$ & $199(99.0)$ & $398(98.3)$ & 0.231 \\
Yes & $5(2.5)$ & $2(1.0)$ & $7(1.7)$ & \\
\hline Complications & & & & 0.658 \\
No & $146(71.6)$ & $149(73.2)$ & $295(72.8)$ & \\
Yes & $58(28.4)$ & $52(26.8)$ & $110(27.2)$ & \\
\hline
\end{tabular}

$R G$ and $P G$, respectively. The frequency of altered results was higher in the PG for $C B C(p=0.009)$, serum urea and creatinine concentration ( $p=0.005)$, PT/aPTT $(p=0.008)$, blood glucose $(p<0.001)$, and chest $X$-ray $(p<0.001)$. Serum electrolyte concentration and ECG did not reveal statistical significance between the groups (Table 2). The PG underwent less POCE than the RG $(p<0.001)$ for all types of exams except for the category supplementary exams ( $p=0.158$ ) (Figure 2). The POCE mean of the PG was $2.98 \pm 2.04$. Fifty additional exams were requested, 29 in the routine group and 21 in the protocol group, with no statistical difference between the groups.

There were conduct changes caused by absence or altered outcome of the exams in seven surgical procedures ( $1.8 \%$ of operations), with five cases $(2.5 \%)$ in the RG and two cases (1.0\%) in the PG $(p=0.231)$ (Table

Figure 1. Protocol for requesting preoperative exams.

\begin{tabular}{|l|l|l|l|l|l|l|l|l|}
\hline & & CBC & Electrolytes & Ur/Cr & Gluc/HbA1c & PT/aPTT & EKG & PPFR \\
\hline $\mathrm{A}$ & $0-50$ years & & & & & & & \\
\cline { 2 - 10 } $\mathrm{G}$ & $50-60$ years & & & & & & & \\
\cline { 2 - 9 } & $>60$ years & & & & & & & \\
\hline
\end{tabular}

\begin{tabular}{l|l|l|l|l|l|l|l|l|} 
D & SAH & & & & & & \\
I & Cardiac & & & & & & \\
S & Pulmonary & & & & & & \\
E & Myeloproliferative & & & & & & \\
A & Hepatic & & & & & \\
S & Renal & & & & & \\
E & Hemorragic & & & & & & \\
S & Diabetes & & & & & & \\
\cline { 2 - 7 } & & & & & & \\
\hline
\end{tabular}

\begin{tabular}{|l|l|l|l|l|l|l|l|l|}
\hline $\mathrm{D}$ & Diuretics & & & & & & & \\
\hline & Corticoids & & & & & & & \\
$\mathrm{U}$ & Anticoagulants & & & & & & & \\
G & Myelotoxic & & & & & & & \\
$\mathrm{S}$ & & & & & & & \\
\hline
\end{tabular}

\begin{tabular}{|c|l|l|l|l|l|l|l|l|}
\hline $\mathrm{S}$ & Minor & & & & & & & \\
\hline & Medium & & & & & & & \\
Z & Major & & & & & & & \\
E & & & & & & & \\
\hline
\end{tabular}

\section{Do not request}

Request

CBC: Complete Blood Count; U/Cr: urea/creatinine; Gluc/HbA1c: glycemia/glycated hemoglobin; PT/aPTT: prothrombin time and activated partial thromboplastin time; EKG: resting electrocardiogram; PPFR: pleuropulmonary fields radiography. 
Table 4. Influence of exams on surgical-anesthetic conduct and of the sample characteristics on operative complications.

\begin{tabular}{|c|c|c|c|}
\hline \multirow[b]{3}{*}{$C B C$} & \multicolumn{3}{|c|}{ Change in conduct } \\
\hline & No $(\%)$ & Yes (\%) & Gross OR $(95 \% \mathrm{Cl})$ \\
\hline & & & \\
\hline Normal & $251(77.2)$ & $2(28.6)$ & 1.00 \\
\hline Altered & $74(22.8)$ & $5(71.4)$ & $8.48(1.61-44.60)$ \\
\hline \multicolumn{4}{|l|}{ PT/aPTT } \\
\hline Normal & $212(96.8)$ & $3(50.0)$ & 1.00 \\
\hline \multirow[t]{3}{*}{ Altered } & $7(3.2)$ & $3(50.0)$ & $30.28(5.17-177.55)$ \\
\hline & \multicolumn{3}{|c|}{ Hypotension } \\
\hline & No $(\%)$ & Yes (\%) & Gross OR $(95 \% \mathrm{Cl})$ \\
\hline \multicolumn{4}{|c|}{ Associated Diseases } \\
\hline 0 & $108(31.6)$ & $13(20.6)$ & 1.00 \\
\hline 1 & $136(39.8)$ & $24(38.1)$ & $1.46(0.71-3.01)$ \\
\hline 2 & $72(21.1)$ & $15(23.8)$ & $1.73(0.77-3.85)$ \\
\hline \multirow[t]{3}{*}{3 or more } & $28(7.6)$ & $11(17.5)$ & $3.51(1.41-8.73)$ \\
\hline & \multicolumn{3}{|c|}{ Other cardiovascular complications } \\
\hline & No $(\%)$ & Yes (\%) & Gross OR $(95 \% \mathrm{Cl})$ \\
\hline \multicolumn{4}{|l|}{ MET } \\
\hline$<4$ & $44(11.7)$ & $9(30.0)$ & $3.13(1.30-7.53)$ \\
\hline$\geq 4$ & $245(65.3)$ & $16(53.3)$ & 1.00 \\
\hline$\geq 10$ & $86(22.9)$ & $5(16.7)$ & $0.89(0.31-2.50)$ \\
\hline \multicolumn{4}{|l|}{ ASA } \\
\hline$(\mathrm{I})$ & $105(28.0)$ & $6(20.0)$ & 1.00 \\
\hline ॥ & $242(64.5)$ & $19(63.3)$ & $1.37(0.53-3.54)$ \\
\hline III & $28(7.5)$ & $5(16.7)$ & $3.12(0.89-10.99)$ \\
\hline
\end{tabular}

PT/aPTTÇ prothrombin time and activated partial thromboplastin time; ASA: physical status according to the American Society of Anaesthesiologists; Met: metabolic equivalents (activity index of Duke).

3). Considering the change in conduct and the POCE, we observed statistically significant associations, and the chance of conduct change was 8.48 times higher for the altered blood count when compared to the normal CBC. For the evaluation of the PT/aPTT, this estimate was even higher ( $\mathrm{OR}=30.28,95 \% \mathrm{Cl}=5.17-177.55)$. However, one must exercise caution with this finding because of the size of the confidence interval (Table 4).

The frequency of complications was 58 cases in the RG $(28.43 \%)$ and 54 cases in the PG $(26.86 \%)$, with $p=0.658$ (Table 3). There was an increase in the risk estimates in the association between the characteristic "associated diseases" and the occurrence of the complication "hypotension", with a cumulative effect according to the increase in the number of associated diseases, with a statistically significant result (OR=3.51, 95\% Cl= 1.41-8.73) (Table 4). We observed a positive association between the ASA variable and the other cardiovascular complications. Nonetheless, the values found were not statistically significant. When the association between this group of complications and the classification of MET was evaluated, we observed that individuals classified as MET's $\leq 4$ presented a three times greater chance of complications when compared with the group classified with MET's $\geq 4$ (Table 4). 


\section{DISCUSSION}

Several studies seek to analyze the effectiveness of preoperative examinations in modifying surgical anesthetic management and its impact on the frequency of perioperative complications. One of the pioneer studies was a retrospective study from Kaplan et al. ${ }^{12}$, which concluded that only $4.3 \%$ of the routine exams had abnormal results and of those, $0.17 \%$ had some clinical significance. Similarly, Soares et al. ${ }^{5}$, in a descriptive study, found $2.25 \%$ of changes in the results of such exams and only $0.38 \%$ were cause for behavior change. Differently from these findings, our study revealed that in the RG group $14.9 \%$ of the exams were altered and there was a change in surgical anesthetic management in $2.5 \%$ of operations. These data are similar to those found by Guerra et al. ${ }^{13}$, who conducted a retrospective study and observed $19.8 \%$ of abnormalities in routine preoperative exams, which led to a change of conduct in $1.8 \%$ of cases. Benarroch-Gampel et al. ${ }^{14}$, in a retrospective cohort using data from the American National Surgical Quality Improvement Program of patients with a profile similar to that of our sample, found that $61.6 \%$ had at least one abnormal test result. Roizen ${ }^{15}$ observed that, assuming that the tests are independent of each other, the more tests are requested, the greater the likelihood of finding abnormal results if we take into account issues such as the specificity and sensitivity of such tests and that routine tests are not suitable instruments to identify unknown diseases, are not cost effective, have no impact on surgical anesthetic management, and potentially add risks to the patient and medical-legal problems.

Regardign selective exams, they were altered in $29.1 \%$ of our study. Charpak et al. ${ }^{16}$, in an analysis of surgical patients who underwent a chest X-ray with a clinical indication identified that $52 \%$ had abnormalities in the examination, but in only $23 \%$ of the cases, these abnormalities were not expected by anamnesis and physical examination. Also in this study, the observed changes modified the anesthetic-surgical management in only $5 \%$ of the cases. Chung et al. ${ }^{17}$, in a randomized clinical trial of patients undergoing outpatient surgical procedures, found $11.5 \%$ of selective exams with
Figure 2. Reduction of the number of exams with the Protocol.

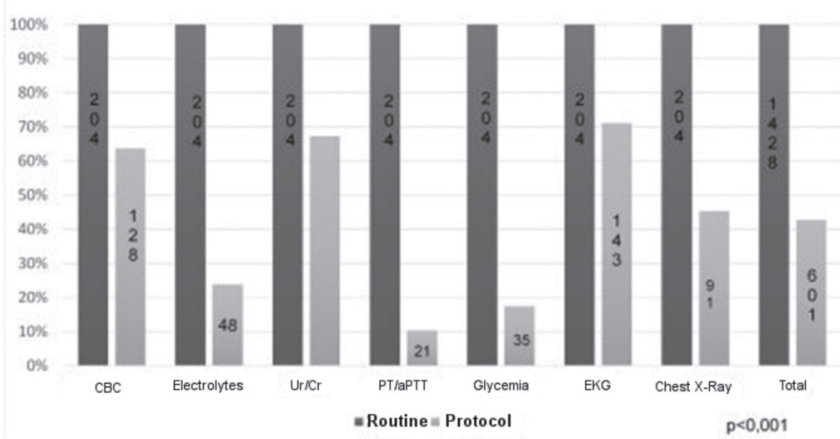

Ur/Cr: urea/creatinine; PTIAPTT: prothrombin time and activated thromboplastin time; EKG: resting electrocardiogram.

abnormal results and only one change in perioperative care was detected. In these studies, it can be concluded that abnormalities found in selective preoperative exams can often be anticipated by anamnesis and physical examination and/or reflect physiological changes in aging, and have no impact on surgical planning and anesthetic management, such as observed in our study. These findings have implications not only on the direct and indirect financial costs of this practice, but also on the quality of the preoperative evaluation. Thus, we share the opinion of Roizen ${ }^{18}$, which says that the real question is not to do or not to do exams, but rather to establish the clinical characteristics of the surgical patient through a careful anamnesis and physical examination and not to replace them by the complementary exams requests.

In the last 20 years several medical societies and health technology institutes $1,2,7-9$ have developed protocols with the purpose of reducing the routine of requesting non-selective preoperative exams, a practice that found no evidence support. One of the first studies was that of Fischer et al. ${ }^{19}$, who compared patients in preoperative elective surgery distributed in two groups: in one group the tests were routinely ordered and in the other they were based on the presence of specific clinical conditions. These authors observed a reduction of $55.14 \%$ in the number of exams requested without there being an increase in the procudures' cancellations.

Similarly, the present study found a reduction of $57.3 \%$ in the requests for preoperative exams between the study groups. This reduction ranged from $28.8 \%$ for ECG to $89.6 \%$ for PT/aPTT. When analyzing only the exams done by the PG group, we found that $22.4 \%$ of 
the patients did not undergo any tests and only $1 \%$ had all the examinations contemplated in the protocol.

When testing the association between the mean number of exams and the characteristics of this group, we observed that $68.4 \%$ of the patients classified as ASA I did not undergo any tests and $70.8 \%$ of the patients classified as ASA III underwent four or more tests $(p<0.001)$. Regarding the associated diseases, we observed that in the set of patients with three or more diseases, $89 \%$ underwent four or more exams $(p<0.001)$, and when analyzing the distribution of exams by age group, we found that in patients with 60 years or more, $75.2 \%$ had four or more exams $(p<0.001)$. As for the type of anesthesia, $91.2 \%$ of patients submitted to peribulbar anesthesia underwent four or more exams $(p=0.006)$, and of the patients submitted to local anesthesia with sedation, $42.9 \%$ did not undergo any examination, and $14.3 \%$ underwent only one exam ( $p=0.008)$.

In a study involving six hospitals in Switzerland, Barazzoni et al. ${ }^{10}$ investigated the impact and adherence to guidelines for requesting preoperative exams over six time intervals before and after implementation of these guidelines. There was a $81 \%$ reduction in coagulogram requests and $43 \%$ in ECG requests. The reduction was more significant in the ASA I and II patients, and did not mean an increase in the number of perioperative complications or surgical mortality. In a study investigating the impact after two years of the implementation of guidelines for requesting preoperative exams in outpatient orthopedic operations, Mancuso ${ }^{9}$ found a reduction, varying from 23 to $44 \%$, in the mean number of exams requested without an increase in the frequency of complications or hospital readmissions. When analyzing, by group of patients and type of anesthesia, the group with a greater number of associated diseases and those who underwent general anesthesia did not present a reduction in the number of exams. In contrast, Finegan et al. ${ }^{11}$ performed a prospective cohort study in a hospital with a similar profile to ours and compared a group of patients who had their exams requested in an established preoperative evaluation practice with a group of patients whose preoperative exams were requested by different health professionals who received prior guidance on evidence- based guidelines. In this study, there was no reduction in the average number of exams found, complications were higher in the group of exams selected, but these were not related to the exams' results or to their absence. In the present study, when submitting a group of patients to the proposed protocol, we observed a reduction in the mean number of exams requested, similar to the findings of Mancuso ${ }^{9}$ and Barazzoni ${ }^{10}$, that is, a more pronounced reduction of exams requests for those younger patients, without associated diseases, classified as ASA I and undergoing small operations (procedures with local anesthesia and sedation). This significant reduction in the number of requested exams was not accompanied by increase in the incidence of perioperative complications or in the request for exams complementary to the protocol.

On the other hand, Chung et al. ${ }^{17}$ tested a local protocol for preoperative exams versus a group of patients who did not undergo any preoperative exams and found no difference in the frequencies of complications or hospital readmissions. In a multicenter, randomized trial, Schein et al. ${ }^{20}$ tested the complete elimination of preoperative exams in cataract surgery and found the same incidence of intra- and postoperative complications in the group without exams compared with the group with exams, concluding that preoperative exams do not contribute to surgical safety. It should be emphasized that the patients' profile in these studies is different from ours, since the analyzed only small, outpatient operations, whereas in our sample predominated mid-size surgeries, requiring hospitalization.

We found seven cases of conduct change in this study: in four surgical procedures, there was a change in the anesthetic technique (replacement of the combined epidural/general technique with general anesthesia) caused by thrombocytopenia in two cases and by changes in PT/ aPTT in the others. Two surgical procedures were postponed due to lack of an additional protocol exam (echocardiogram) and one procedure was postponed by an altered exam (hyperglycemia). When analyzing the association between the cases of altered conduct and the abnormal results of exams, we found that the only exams capable of influencing surgical anesthetic management were CBC and PT/aPTT, a result similar to that found by Guerra ${ }^{13}$. 
In the present study, the frequency of complications was $28.4 \%$ and $26.8 \%$, respectively, in the Routine and Protocol groups, with no statistical significance. This result presents rates higher than those observed by several authors ${ }^{9,11,17,20}$, which ranged from $0.8 \%$ to $6 \%$ for the routine group and $1.4 \%$ to $6.0 \%$ for the selective exams group or no exam. We believe that this difference is due to the fact that, for the most part, these studies were carried out on samples from patients undergoing small and outpatient surgeries, with the exception of the Finegan ${ }^{10}$ study. In our study, hypotension was the most common complication, with 63 cases, followed by other cardiovascular complications, with 30 events. When analyzing the association of complications with the sample's characteristics, we found a statistically significant association with the presence and number of associated diseases and functional classification (MET's).
Such associations were not observed in the study by Schein et $a / .{ }^{20}$, nor in the one by Chung et al. ${ }^{17}$. However, there are studies in the medical literature associating surgical morbidity and mortality with preoperative conditions of the physical state, clinical compensation of associated diseases, besides the type and nature of the executed procedure ${ }^{21,22}$. Studies on perioperative complications are difficult to perform. Although this discussion fits the objectives of this study, it is important to note that perioperative morbidity does not have any association with the number of exams requested, nor with altered results of such exams, a fact observed both by us and by other authors ${ }^{9,11,17,19,20}$.

We conclude that the protocol we used was effective in eliminating a significant number of complementary exams requested without clinical indication, without, however, causing an increase in perioperative morbidity and mortality.

\title{
R E S U M O
}

\begin{abstract}
Objetivos: avaliar o impacto do uso de um protocolo local de solicitações de exames pré-operatórios na redução do número de exames solicitados e na ocorrência de alterações na conduta anestésico-cirúrgica e de complicações perioperatórias. Métodos: ensaio clínico randomizado, cego, realizado no Hospital Universitário Gaffrée e Guinle com 405 pacientes candidatos à operação eletiva divididos randomicamente em dois grupos segundo a prática de solicitação de exames pré-operatórios: grupo Rotina com exames solicitados de maneira não seletiva e grupo Protocolo com exames solicitados de acordo com o protocolo em estudo. Exames em estudo: hemograma, coagulograma, glicemia, eletrólitos, ureia e creatinina, ECG e radiografia de tórax. Desfechos primários: alterações na conduta anestésico-cirúrgica motivadas por exames anormais, redução do número de exames solicitados após o uso do protocolo e complicações perioperatórias. Resultados: foi observada diferença significativa $(p<0,001)$ no número de exames com resultados alterados entre os dois grupos $(14,9 \% \times 29,1 \%)$ e redução de $57,3 \%$ no número de exames pedidos entre os dois grupos $(p<0,001)$, mais acentuada nos pacientes de menor faixa etária, ASA I, sem doenças associadas e submetidos a procedimentos de menor porte. Não houve diferença significativa na frequência de alterações de conduta motivada por resultado de exames, nem de complicações entre os dois grupos. Na análise multivariada hemograma e coagulograma foram os únicos exames capazes de modificar a conduta anestésico-cirúrgica. Conclusão: o protocolo proposto foi efetivo em eliminar um quantitativo significativo de exames complementares sem indicação clínica, sem que houvesse aumento na morbidade e mortalidades perioperatórias.
\end{abstract}

Descritores: Cuidados Pré-Operatórios. Testes Diagnósticos de Rotina. Guia de Prática Clínica. Complicações Pós-Operatórias.

\section{REFERENCES}

1. Committee on Standards and Practice Parameters., Apfelbaum JL, Connis RT, Nickinovich DG; American Society of Anesthesiologists Task Force on Preanesthesia Evaluation., Pasternak LR, et al. Practice advisory for preanesthesia evaluation: an updated report by the American Society of Anesthesiologists Task Force on Preanesthesia Evaluation. Anesthesiology. 2012;116(3):522-38.

2. NCCAC. Preoperative tests, the use of routine preoperative tests for elective surgery-Evidence, Methods and Guidance [Internet]. London: Nice; 2003. [cited
2015 Out 28]. Available from: https://www.nice.org. uk/guidance/cg3

3. Bader AM, Hepner DL. Update on preprocedure testing. In: Fleisher LA. Evidence-based Practice of Anesthesiology. 3rd ed. Philadelphia: Elsevier; 2013. p.8-13

4. Iglesias AC. Cuidados pré-operatórios e risco cirúrgico. In: Clínica Cirúrgica do Colégio Brasileiro de Cirurgiões. Rio de Janeiro: Atheneu; 2010. p.63-92.

5. Soares DS, Brandão RRM, Mourão MRN, Azevedo VLF, Figueiredo AV, Trindade ES. Relevância de exames de rotina em pacientes de baixo risco submetidos à cirurgias de pequeno e médio porte. Rev Bras Anestesiol. 2013;63(2):197-201. 
6. Johansson T, Fritsch G, Flamm M, Hansbauer B, Bachofner N, Mann E, et al. Effectiveness of non-cardiac preoperative testing in non-cardiac elective surgery: a systematic review. Br J Anaesth. 2013;110(6):926-39.

7. Eagle KA, Berger PB, Calkins H, Chaitman BR, Ewy GA, Fleischmann KE, et al. ACC/AHA guideline update for perioperative cardiovascular evaluation for noncardiac surgery--executive summary. A report of the American College of Cardiology/American Heart Association Task Force on Practice Guidelines (Committee to Update the 1996 Guidelines on Perioperative Cardiovascular Evaluation for Noncardiac Surgery). Anesth Analg. 2002;94(5):1052-64.

8. Fleisher LA, Fleischmann KE, Auerbach AD, Barnason SA, Beckman JA, Bozkurt B, et al. 2014 ACC/AHA guideline on perioperative cardiovascular evaluation and management of patients undergoing noncardiac surgery: executive summary: a report of the American College of Cardiology/American Heart Association Task Force on Practice Guidelines. Circulation. 2014;130(24):2215-45.

9. Mancuso CA. Impact of new guidelines on physicians' ordering of preoperative tests. J Gen Intern Med.1999;14(3):166-72.

10. Barazzoni F, Grilli R, Amicosante AM, Brescianini $S$, Marca MA, Baggi $M$, et al. Impact of end user involvement in implementing guidelines on routine pre-operative tests. Int J Qual Health Care. 2002;14(4):321-7.

11. Finegan BA, Rashiq S, McAlister FA, O'Connor P. Selective ordering of preoperative investigations by anesthesiologists reduces the number and cost of tests. Can J Anaesth. 2005;52(6):575-80.

12. Kaplan EB, Sheiner LB, Boeckmann AJ, Roizen MF, Beal $S L$, Cohen SN, et al. The usefulness of preoperative laboratory screening. JAMA. 1985;253(24):3576-81.

13. Guerra ME, Pereira CS, Falcão DP, Sigwald MF, Skinovsky J. Análise da relevância dos exames laboratoriais pré-operatórios solicitados em cirurgias eletivas em um hospital universitário. Rev médico resid. 2012;14(1):1-7.

14. Benarroch-Gampel J, Sheffield KM, Duncan CB, Brown KM, Han Y, Townsend CM Jr, et al. Preoperative laboratory testing in patients undergoing elective, lowrisk ambulatory surgery. Ann Surg. 2012;256(3):518-28.

15. Roizen MF. Preoperative laboratory testing: necessary or overkill? Can J Anesth. 2004;51(Suppl 1):R53.

16. Charpak Y, Blery C, Chastang C, Szatan M, Fourgeaux B. Prospective assessment of a protocol for selective ordering of preoperative chest $x$-rays. Can J Anaesth. 1988;35(3 (Pt 1)):259-64.

17. Chung F, Yuan H, Yin L, Vairavanathan S, Wong DT. Elimination of preoperative testing in ambulatory surgery. Anesth Analg. 2009;108(2):467-75.

18. Roizen MF. More preoperative assessment by physicians and less by laboratory tests. N Engl J Med. 2000;342(3):204-5.

19. Fischer SP. Development and effectiveness of an anesthesia preoperative evaluation clinic in a teaching hospital. Anesthesiology. 1996;85(1):196-206.

20. Schein OD, Katz J, Bass EB, Tielsch JM, Lubomski LH, Feldman MA, et al. The value of routine preoperative medical testing before cataract surgery. Study of Medical Testing for Cataract Surgery. N Engl J Med. 2000;342(3):168-75.

21. Pedersen T, Eliasen K, Henriksen E. A prospective study of mortality associated with anaesthesia and surgery: risk indicators of mortality in hospital. Acta Anaesthesiol Scand. 1990;34(3):176-82.

22. Schwartzman UP, Batista KT, Duarte LTD, Saraiva RÂ, Fernandes MCBC, Costa VV, et al. Complicação anestésica em hospital de reabilitação. A incidência tem relação com a consulta pré-anestésica? Rev Bras Anestesiol. 2014;64(5):357-64.

Received in: 22/09/2016

Accepted for publication: 05/12/2016

Conflict of interest: none.

Source of funding: none.

\section{Mailing address:}

Monica Loureiro Santos

E-mail: monicareg_loureiro@yahoo.com.br gngilson@gmail.com 